\title{
30. COVID-19 and resilience innovations in food supply chains
}

\author{
Thomas Reardon and Johan Swinnen
}

The COVID-19 pandemic has triggered intense discussions about the vulnerability of the world's food systems and food supply chains (FSCs) and about the roles of different types of supply chains, such as local vs. global, in providing food security. We know that the spread of the novel coronavirus and government-imposed lockdowns and other restrictions have had a range of impacts on FSCs, and triggered a variety of creative innovations to keep supply chains running.

To guide government policy responses going forward, and to facilitate a shift to more resilient FSCs in the long run, we need to understand several things: the role of various types of supply chains in food security; how resilient they have - or have not - been to the pandemic's impacts; and what innovations are now emerging to improve their resilience.

Here, we distinguish between global chains (where the food or agricultural raw material is produced in one country and consumed in another) and domestic chains (where food is produced and consumed in the same country). Within domestic chains, it is useful to distinguish between those relying on small and medium-sized enterprises (SMEs) in logistics, trade, processing, and retailing; and those dominated by large-scale enterprises, including fast food chains, supermarkets, large processors, and big logistics firms.

While there are obviously important differences across commodities and countries, available data suggest that domestic supply chains, especially those dominated by SMEs, are by far the most important for supplying food to consumers in developing countries. Rough estimates suggest that, on average for South Asia and Africa south of the Sahara, domestic chains account for between 75\% and $90 \%$ of food consumed, of which the vast majority comes through SME-dominated chains and up to $20 \%$ through large-scale enterprises. Global chains account roughly for $15 \%$ to $20 \%$ of food consumption in these regions, with a positive correlation between GDP and their share. ${ }^{1}$

Pandemic-related disruptions in supply chains are concentrated in their labor-intensive segments. In general, supply chains in rich countries have been more resilient because they are more capital- and knowledge-intensive. Notable exceptions are harvesting that depends on migrant labor; labor-dense processing such as in meat processing in the United States; and obviously restaurants and other food-service sector firms.

Still, there are important differences among FSCs in developing countries. Global FSCs have been more resilient because trade is mostly undertaken by large enterprises in coordinated and capital-intensive supply chains that can mostly adjust to disruptions geographically and temporally, and somewhat in product composition. While there is much concern about COVID-19 affecting trade in

1 Barrett, C., T. Reardon, J.Swinnen, and D. Zilberman, 2020, "Agrifood Value Chains Revolutions in Low and Middle Income Countries," unpublished manuscript. See appendix. 
perishables, most extraregional trade is organized through large capital-intensive firms. ${ }^{2}$ These large trading companies can reduce risk and adjust to shocks as they are more flexible in switching global sourcing and destination regions and in diversifying and shifting stocks to manage risk - as they already do to manage risks from climate shocks (Reardon and Zilberman 2018).

Within domestic FSCs, COVID-19 and lockdowns have mixed effects. Large-scale companies are generally less labor intensive but rely more on hired labor (affected especially by lockdowns), while SMEs are more labor intensive, but use more family labor. Wholesaling and logistics operations, such as third-party logistics firms (3PLS) in trucking and transport, which are very important for food transport in Africa south of the Sahara, are disrupted by mobility restrictions and wholesale market restrictions. These also affect farm input distribution in rural areas. These differences matter for processing, trade, and logistics, and also apply to the farm sector. Larger mechanized farms are less affected by pandemic restrictions, but those that depend on hired labor have felt an impact. Hired farm labor is relatively rare in Africa south of the Sahara, except for labor-intensive poultry and horticulture operations, compared to India, for example, where farms depend much more on hired labor (Reardon et al. 2020).

Supermarkets and large processors in developing countries depend largely on SME wholesalers, but the largest companies - such as Future Group, a leading supermarket chain in India - tend to have their own logistics and procurement units. This allows them more control and coordination to maximize their sourcing in the face of constraints. SMEs have to take what they can get.

\section{Innovations and food chain resilience}

Supply chain participants have introduced a series of innovations in response to COVID-19 and restrictions. So far, there is little systematic data available on these entrepreneurial and creative institutional responses. Anecdotal information suggests that these innovations are important and could have a major impact on the future of FSCs in developing countries - in particular buttressing their resilience. Entrepreneurs are telling us that "what we thought would only be possible over the next two decades is now being introduced in a few months."

There are several kinds of mutually supporting innovations:

Social innovations. Labor interactions in value chains are being reorganized to reduce shortfalls of access to labor, while guaranteeing worker safety. This involves:

- Increased flexibility of labor sourcing and timing, including facilitating the movement and safety of workers. For example, in Nigeria large chicken processors are busing workers to plants and increasing the number of shifts so there are fewer workers in the plant at one time.

- Increased flexibility by replacing workers with machines. This is easier for large farms and large firms, as they are more mechanized to begin with. This of course implies a challenge of reduced employment both in the short and long term.

2 For example, Bakhresa, the biggest food processor in East Africa, imports wheat that then goes to big mills; or see activities of companies like Charoen Pokhphand Food in Asia (see AGRA 2019 and Reardon and Zilberman 2018). 


\section{Business strategy innovations in systems of input procurement and output or service market-}

ing. The business adjusts its systems to mitigate risks such as a rapid drop in demand among its usual clientele, or a sudden blockage to its sourcing a key input. The changes are parallel to those made for labor:

- Increased flexibility in marketing by diversifying the customer base and ways to reach consumers. For example, restaurants quickly moved from on-site service to delivery (as we discuss more below). Likewise, a supplier might have previously targeted only food service and then shifted to retail or direct sales to consumers.

- Increased flexibility in sourcing by diversifying logistics; diversifying input types to get what's available; and diversifying geographic sources to reduce risk. The latter resembles actions firms were taking pre-pandemic to address climate risk (Reardon and Zilberman 2018).

Technological innovations. Introducing technologies that improve hygiene while requiring fewer personal interactions between workers, and between the firm and customers. Examples include contactless delivery and e-commerce for customers.

Financial resilience innovations. Large companies are also creating financial resilience innovations for SMEs. In India, Swiggy, a fast-growing food delivery app and logistics company, delivers for 40,000 restaurant partners, helping them with its "jumpstart package" to recover sales, while the Swiggy Capital Assist Programme helps pay for hygiene and distancing upgrades. In Singapore, Unilever Foods Solutions partnered with e-commerce platform Carousell to launch \#SupportLocal, enabling 180,000 food and beverage firms in Southest Asia to connect online with local diners. Unilever also shifted to advance payments to small farmers and credit to small retailers to support their resilience over the past three months.

\section{Growth of e-commerce}

E-commerce is a particularly vibrant example of innovation. While the use of e-commerce in most developing countries has generally been low, in some it was growing rapidly even before COVID-19. For example, in China - with more than a billion people now online - e-commerce was increasingly widespread, even in rural areas.

Apart from COVID-19, the demand-side drivers of e-commerce are similar to those of the "supermarket revolution": increasing opportunity costs of time for shopping, magnified by traffic time with urban congestion, enhances the benefits of one-stop-shopping at supermarkets - and now e-commerce.

The supply-side drivers are (1) rapid diffusion of digital technologies, internet, computers, and mobile phones; (2) intense competition and investments in the past decade by e-commerce multinationals (first Amazon, then also Alibaba) joined by e-commerce domestic firms (such as Flipkart in India and Jumia in Nigeria); (3) e-commerce by supermarket chains (such as the Walmart-Flipkart joint venture in India); and (4) complementary investments by logistics firms (such as FedEx and local counterparts), delivery firms (such as Instacart and Deliveroo), and mobile money firms. 
COVID-19 has accelerated the first wave of e-commerce diffusion already underway led by large companies, and - encouraged by governments and NGOs facilitating e-commerce platforms - created a second wave into the realm of SMEs in trade, logistics and delivery, and mobile money firms.

E-commerce is growing fastest in Asia, but is increasingly spreading in Africa too. Large e-commerce companies are rapidly developing both retail services and intermediation services to help SMEs. In response to COVID-19, Alibaba has scaled up local deliveries of fresh produce to Chinese consumers. It adapted its online shopping site Taobao to provide deliveries in "one hour" with "hyperlocal fulfillment" including from SME retailers and independent chains (Song 2019; Chou and So 2020). In India, Flipkart is growing fast during the COVID-19 crisis and developed a "hyperlocal delivery" grocery service linking SME suppliers with domestic supermarket chains like Vishal Mega Mart with its e-commerce operations (Economic Times 2020, 2020). In Nigeria, Jumia has seen its year-on-year sales quadruple with COVID-19 (Kazeem 2020).

SMEs are also starting their own e-commerce services to cope with COVID-19. In Thailand, SMEs are selling food directly to consumers via Facebook and local delivery apps over mobile networks (LeesaNguansuk 2020). Malaysia-based MyFishman.com provides fresh seafood subscriptions and delivery services to local fishermen (Harper 2020).

Business associations and governments are also facilitating e-commerce during COVID-19. In China, the China Agricultural Wholesale Market Association began working with e-commerce and mobile chat groups to link suppliers and buyers (Fei and Ni 2020). In Myanmar, the Myanmar Pulses, Beans \& Sesame Seeds Merchants Association started an e-platform to link domestic suppliers and processors and exporters. ${ }^{3}$ In India, the National Informatics Centre created the Kisan Rath mobile app to help farmers and traders find vehicles to move their fruits and vegetables to market (Financial Express Online 2020).

\section{Lessons and recommendations}

The resilience of domestic supply chains is crucial to food security in developing countries. They are dominated by SMEs that have been particularly vulnerable to pandemic-related impacts, and to a lesser degree by emerging large enterprises and global value chains, both somewhat better equipped to weather COVID-19 shocks. Domestic FSCs have been particularly disrupted downstream in food service and retail, moderately in processing, and much less so in farming, except where hired labor is important.

Steps by the private sector - both large firms and SMEs - include introduction of flexibility in labor access, in product procurement, in marketing, in technology, and in financial resilience. In many cases the innovations by large firms, such as with e-platforms and credit, have made SMEs' suppliers and retailers more resilient. The expansion of e-commerce has accelerated, and we expect that to continue post-pandemic. E-commerce has helped SMEs deliver food to consumers under lockdowns and other constraints, and added to the resilience of the supply chains in developing regions.

3 We are grateful to Curtis Slover of UNOPS for this field observation. 
Many government officials and donors have worried that the pandemic would simply stop the operation of supply chains - requiring them to step in and replace the market. This would be neither possible, given the massive scale of the market and food demand, nor necessary in many cases, given the steps supply chain actors are taking to adapt and build resilience. Of course, these efforts have not been universally successful - there is obvious evidence of real dips in business activity and demand, with accompanying employment losses. But the many cases of innovation we identify paint a picture of a private sector, as well as associations and governments, keen and able to innovate. Governments and development partners would do well to support that innovation with investments in hard and soft infrastructure and an enabling business and commerce environment for both SMEs and large companies eager to play their part in resilience for food security during the pandemic and recovery - and in rebuilding for the future.

Originally published July 6, 2020. 